\title{
Tetramethylpyrazine inhibits angiotensin II-induced cardiomyocyte hypertrophy and tumor necrosis factor- $\alpha$ secretion through an NF-кB-dependent mechanism
}

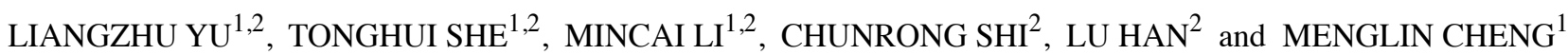 \\ ${ }^{1}$ Hubei Province Key Laboratory on Cardiovascular, Cerebrovascular and Metabolic Disorders, \\ ${ }^{2}$ School of Basic Medicine, Hubei University of Science and Technology, Xianning, Hubei 437100, P.R. China
}

Received March 15, 2013; Accepted June 13, 2013

DOI: $10.3892 /$ ijmm.2013.1436

\begin{abstract}
Tetramethylpyrazine (TMP), a bioactive compound isolated from the Chinese herb, Ligusticum wallichii Franchat, has been reported to play a protective role in cardiac diseases. However, the cellular and molecular mechanisms behind the protective effects of TMP on the heart remain to be elucidated. In this study, we aimed to determine the effects of TMP on angiotensin II (Ang II)-induced hypertrophy in neonatal rat cardiomyocytes and its possible mechanisms of action. In addition, we investigated whether TMP regulates tumor necrosis factor- $\alpha$ (TNF- $\alpha)$ secretion and expression. We found that TMP significantly inhibited the Ang II-induced hypertrophic growth of neonatal cardiomyocytes, as evidenced by the decrease in $\left[{ }^{3} \mathrm{H}\right]$ leucine incorporation and $\beta$-myosin heavy chain $(\beta-\mathrm{MHC})$ mRNA expression. TMP inhibited Ang II-stimulated TNF- $\alpha$ protein secretion and mRNA expression in the cardiomyocytes. Further experiments revealed that Ang II increased the level of the phosphorylated form of the transcription factor, nuclear factor $\kappa$-light-chain-enhancer of activated B cells $(N F-\kappa B)$, as well as NF- $\mathrm{B}$-DNA binding activity in the cardiomyocytes; treatment with TMP significantly inhibited the Ang II-induced activation of NF- $\kappa$ B. Furthermore, the inhibition of NF- $\kappa$ B by the specific inhibitor, pyrrolidine dithiocarbamate (PDTC), markedly attenuated the Ang II-induced increase in $\left[{ }^{3} \mathrm{H}\right]$ leucine incorporation, $\beta$-MHC mRNA expression and TNF- $\alpha$ protein secretion. Our findings suggest that TMP inhibits Ang II-induced cardiomyocyte hypertrophy and TNF- $\alpha$ production through the suppression of the NF- $\mathrm{BB}$ pathway, which may provide new insight into the mechanisms underlying the protective effects of TMP in heart diseases.
\end{abstract}

Correspondence to: Dr Liangzhu Yu or Dr Tonghui She, School of Basic Medicine, Hubei University of Science and Technology, 88 Xianning Road, Xianning, Hubei 437100, P.R. China

E-mail: ylz7210281034@163.com

E-mail: xnsth@163.com

Key words: tetramethylpyrazine, hypertrophy, cardiomyocyte, tumor necrosis factor- $\alpha$, nuclear factor- $\kappa \mathrm{B}$

\section{Introduction}

Cardiac hypertrophy, an increase in cardiomyocyte size, has been recognized as an independent risk factor for future cardiovascular morbidity and mortality (1). Angiotensin II (Ang II) has been implicated in cardiomyocyte hypertrophy (2). The hypertrophic effects of Ang II are mediated by several intracellular signaling pathways, including the nuclear factor $\kappa$-light-chainenhancer of activated B cells (NF- $\kappa \mathrm{B}$ ) pathway (3). NF- $\kappa \mathrm{B}$ has been validated as a therapeutic target for the prevention of cardiac hypertrophy and heart failure (4).

Tetramethylpyrazine (TMP, molecular structure shown in Fig. 1C), a biologically active ingredient isolated from the Chinese herb, Ligusticum wallichii Franchat, has been widely used for the treatment of ischemic cardiovascular diseases (5-7). Its pharmacological functions include anti-ischemic (7), anti-inflammatory (8), antioxidant (9) and anti-arrhythmic properties (7). The anti-inflammatory properties of TMP have been reported to involve the suppression of pro-inflammatory cytokines, such as tumor necrosis factor- $\alpha$ (TNF- $\alpha)$ and interleukin-1 $\beta$ (8). These cytokines have been implicated in the pathogenesis of cardiac hypertrophy $(10,11)$. However, the effects of TMP on cardiac hypertrophy and the expression of TNF- $\alpha$ in cardiomyocytes remain unclear.

In light of these observations, we hypothesized that TMP inhibits Ang II-induced cardiomyocyte hypertrophy, and that the modulation of the NF- $\mathrm{B}$ pathway, if present, is responsible for the anti-hypertrophic effects of TMP. Furthermore, in this study, we determined whether TMP regulates the Ang II-stimulated secretion and expression of TNF- $\alpha$ in neonatal rat cardiomyocytes.

\section{Materials and methods}

Reagents. Dulbecco's modified Eagle's medium (DMEM), fetal calf serum and tissue culture reagents were purchased from Invitrogen Corp. (Carlsbad, CA, USA). TMP was obtained from the National Institute for the Control of Pharmaceutical and Biological Products, Beijing, China. $\left[{ }^{3} \mathrm{H}\right]$ leucine was obtained from the China Institute of Atomic Energy, Beijing, China. Pyrrolidine dithiocarbamate (PDTC; an NF- $\mathrm{B}$ inhibitor) was obtained from Sigma-Aldrich (St. Louis, MO, 
USA). All other chemicals were obtained from Sigma-Aldrich, unless otherwise stated.

Cell culture of neonatal rat cardiomyocytes. This study was carried out according to the National Institutes of Health Guide for the Care and Use of Laboratory Animals (NIH Publication no. 85-23, revised 1996). Approval was provided by the Institutional Animal Care and Use Committee at the Hubei University of Science and Technology, Xianning, China. Primary cultures of neonatal rat cardiomyocytes were prepared according to previously published protocols (12) with minor modifications. Briefly, ventricles were excised from 1- to 3-dayold neonatal Sprague-Dawley rats, which were decapitated to isolate the hearts. Subsequently, the ventricular tissues were minced into $\sim 1 \mathrm{~mm}^{3}$ sections and digested using $0.1 \%$ trypsin (Sigma-Aldrich) and 0.1\% collagenase type II (Sigma-Aldrich) in D-Hanks solution and agitated for $7 \mathrm{~min}$ at $37^{\circ} \mathrm{C}$ to dissociate the cardiomyocytes. The remaining tissues were transferred into a fresh enzyme solution and allowed to dissociate for $7 \mathrm{~min}$. This digestion was repeated 5 times. Cell suspensions were collected, centrifuged (5 min, $60 \mathrm{x} \mathrm{g}$ ) and resuspended in DMEM supplemented with 5\% fetal bovine serum. Dissociated cells were pre-plated for $1 \mathrm{~h}$ at $37^{\circ} \mathrm{C}$ to selectively remove nonmyocytes. Non-adherent cardiomyocytes ( $>90 \%$ purity) were plated on 6-well culture plates at a density of $2 \times 10^{5}$ cells $/ \mathrm{ml}$ DMEM containing $10 \%$ fetal bovine serum, $100 \mathrm{U} / \mathrm{ml}$ penicillin and $100 \mu \mathrm{g} / \mathrm{ml}$ streptomycin. Following incubation for $48 \mathrm{~h}$ at $37^{\circ} \mathrm{C} 5 \% \mathrm{CO}_{2}$, the medium was replaced by fetal bovine serum-free medium and the cells were starved for $10 \mathrm{~h}$ prior to the addition of drugs. The cardiomyocytes were subsequently incubated for a further $24 \mathrm{~h}$ with the vehicle (control) or with $0.1 \mu \mathrm{M}$ Ang II in the presence or absence of TMP or NF- $\kappa \mathrm{B}$ inhibitor at the indicated concentrations.

Protein synthesis. Protein synthesis was determined by measuring the incorporation of $\left[{ }^{3} \mathrm{H}\right]$ leucine incorporation into acid-insoluble protein, which is commonly used as evidence of hypertrophy (13). The cells were treated for $24 \mathrm{~h}$ in the presence or absence of 0.1 $\mu \mathrm{M}$ Ang II and TMP (0.001-1.0 mM). $\left[{ }^{3} \mathrm{H}\right]$ leucine $(1 \mu \mathrm{Ci} / \mathrm{ml})$ was added to each culture dish during treatment with the drugs. Subsequently, the cells were washed with PBS and treated with ice-cold 5\% trichloroacetic acid for $1 \mathrm{~h}$ to precipitate the protein. The precipitates were then dissolved in $0.1 \mathrm{M} \mathrm{NaOH}$ solution. The incorporation rate of $\left[{ }^{3} \mathrm{H}\right]$ leucine was quantified by liquid scintillation spectrometry. Each experiment was performed in triplicate.

RNA isolation and real-time PCR. Total RNA was isolated from the cultured neonatal cardiomyocytes using TRIzol reagent (Invitrogen Corp.) according to the manufacturer's instructions. Subsequently, $\sim 2 \mu \mathrm{g}$ of total RNA was reverse transcribed with ReverTra Ace reverse Transcriptase (Toyobo Co., Ltd., Osaka, Japan). The RT reaction product was heated at $95^{\circ} \mathrm{C}$ to terminate the reaction. The expression of $\beta-\mathrm{MHC}, \mathrm{TNF}-\alpha$ and GAPDH mRNA was examined by real-time PCR using a SYBR-Green dye. The primers used were as follows: rat $\beta$-MHC sense, 5'-TAACCCGAGGCAAGCTCACA-3' and antisense, 5'-CACAATCATGCCGTGCTGAC-3' (product size, $120 \mathrm{bp}$ ); rat TNF- $\alpha$ sense, 5'-GCCAATGGCATGGATC TCAAAG-3' and antisense, 5'-CAGAGCAATGACTCCA
AAGT-3' (product size, $357 \mathrm{bp}$ ); rat GAPDH sense, 5'-CTCAT GACCACAGTCCATGCCATC-3' and antisense, 5'-CGGAA GGCCATGCCAGTGAG-3' (product size, 182 bp). Real-time PCR was performed on an iCycler iQ Real-Time Detection System (Bio-Rad Laboratories, Hercules, CA, USA). Amplification involved $1 \mathrm{cycle}$ at $94^{\circ} \mathrm{C}$ for $3 \mathrm{~min}$ for initial denaturation followed by 40 cycles of denaturation for $30 \mathrm{sec}$ at $94^{\circ} \mathrm{C}$, annealing for $30 \mathrm{sec}$ at $60^{\circ} \mathrm{C}$ and extension for $45 \mathrm{sec}$ at $72^{\circ} \mathrm{C}$. All reactions were performed in triplicate and GAPDH served as an internal control. The results were quantified as $\mathrm{Ct}$ values, where $\mathrm{Ct}$ is defined as the threshold cycle of PCR at which the amplified product is first detected and the values are expressed as the ratio of the target gene to the control. The size of the PCR products was confirmed by electrophoresis on $2 \%$ agarose gels with ethidium bromide staining.

Measurement of TNF- $\alpha$ in the culture medium. At the end of the drug treatment, the culture supernatants were harvested, and the level of TNF- $\alpha$ protein was measured using commercial ELISA kits (R\&D Systems, Minneapolis, MN, USA) according to manufacturer's instructions.

Western blot analysis. To elucidate the mechanisms through which TMP exerts its effects on hypertrophic cardiomyocytes, we examined the protein expression of NF- $\mathrm{BB}$ (p-NF- $\mathrm{kB}$ p65).

At the end of the drug treatment, total protein was extracted from the cardiomyocytes using the Protein Extraction kit (Beyotime Institute of Biotechnology, Beijing, China). Protein concentration was measured using the BCA Protein assay kit (Beyotime Institute of Biotechnology). Equal amounts of protein extract were analyzed by $10 \%$ SDS-PAGE and electrotransferred onto an immobilon-P transfer membrane (Millipore, Bedford, MA, USA). The membrane was probed overnight at $4^{\circ} \mathrm{C}$ with primary antibodies against NF- $\kappa \mathrm{B}$ p65 and the phosphorylated

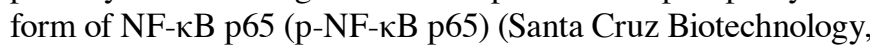
Santa Cruz, CA, USA) Following incubation with HRP-linked rabbit $\operatorname{IgG}$ antibody, the signal was visualized using the ECL Plus system (Beyotime Institute of Biotechnology), according to the manufacturer's instructions. Immunoblotting signals were quantified using Image $\mathbf{J}$ software [National Institutes of Health (NIH), Bethesda, MD, USA].

ELISA-based NF- $\kappa B$ transcription factor activity assay. The cardiomyocytes were treated with the same methods mentioned above, and then nuclear protein was extracted using the Nuclear Protein Extraction kit (Beyotime Institute of Biotechnology) and quantified using the BCA Protein assay kit mentioned above according to the manufacturer's instructions. Nuclear extracts were frozen in liquid $\mathrm{N}_{2}$ and stored at $-70^{\circ} \mathrm{C}$ until use.

ELISA-based NF- $\kappa B$ transcription factor activity assay was performed using a Trans-AM NF- $\mathrm{KB}$ p65 transcription factor assay kit (Active Motif, Carlsbad, CA, USA) according to the manufacturer's instructions. The level of nuclear NF- $\mathrm{kB}$ p65 was expressed as the absorbance at $450 \mathrm{~nm}$ (A450).

Statistical analysis. All values are expressed as the means \pm SEM. Statistical analyses were performed using unpaired Student's t-tests and one-way ANOVA where appropriate. A P-value $<0.05$ was considered to indicate a statistically significant difference. 

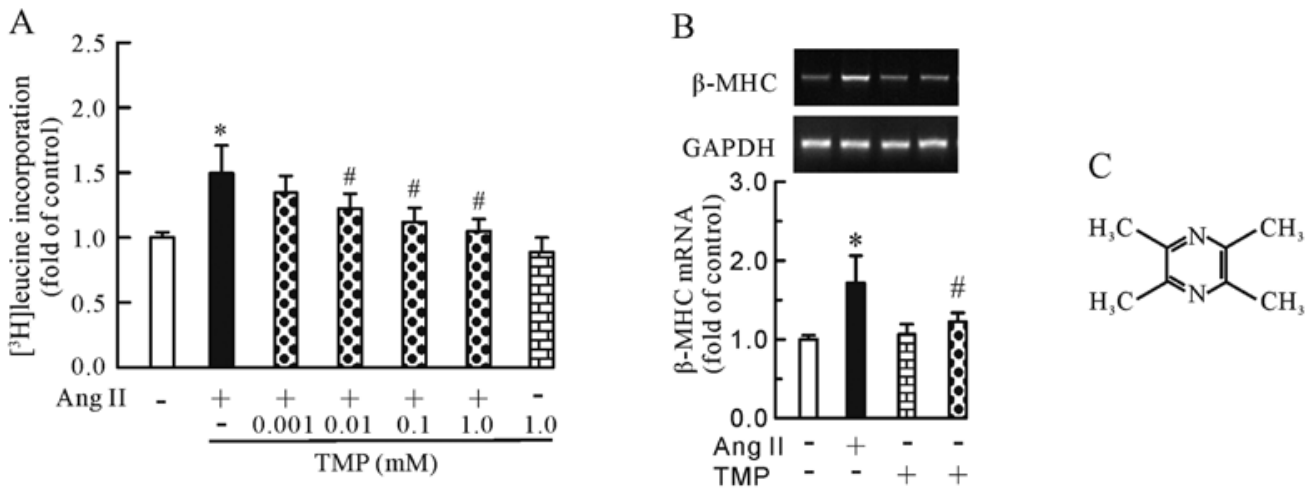

Figure 1. Inhibitory effects of tetramethylpyrazine (TMP) on angiotensin II (Ang II)-induced cardiomyocyte hypertrophy. Cultured cardiomyocytes were treated with $0.1 \mu \mathrm{M}$ Ang II in the presence or absence of TMP at different concentrations as indicated on culture day 3 . After $24 \mathrm{~h}$ of treatment, (A) the incorporation of $\left[{ }^{3} \mathrm{H}\right]$ leucine and (B) $\beta$-MHC mRNA levels were measured. In each experiment, a treatment-to-control ratio was calculated. $\left[{ }^{3} \mathrm{H}\right]$ leucine incorporation was $1460 \pm 65 \mathrm{cpm} /$ well for the control cardiomyocytes treated with diluent. Values are the means \pm SEM of $6-8$ independent trials and are expressed as multiples of the control. ${ }^{*} \mathrm{P}<0.05$ vs. control; ${ }^{\#} \mathrm{P}<0.05$ vs. Ang II alone. (C) Molecular structure of TMP.
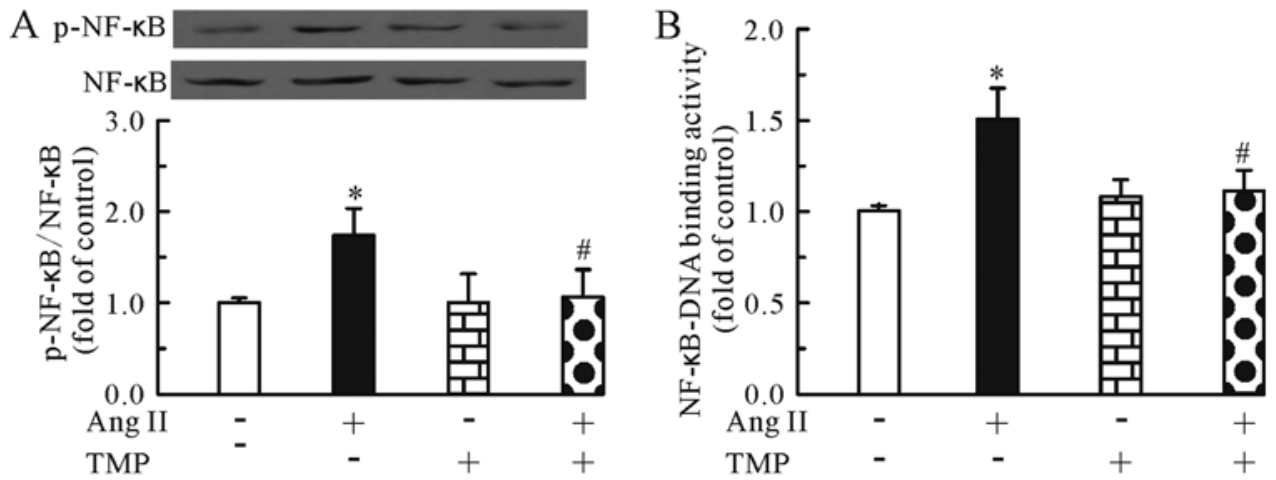

Figure 2. Tetramethylpyrazine (TMP) attenuates angiotensin II (Ang II) increased protein levels of phosphorylated NF- $\mathrm{kB}$ p65 in cardiomyocytes. Cultured cardiomyocytes were treated with $0.1 \mu \mathrm{M}$ Ang II in the presence or absence of $1.0 \mathrm{mM}$ TMP on culture day 3 . After $24 \mathrm{~h}$ of treatment, (A) the protein level of

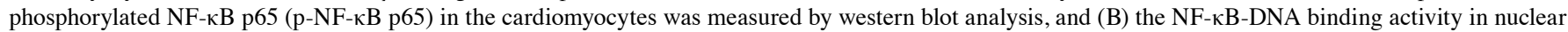
extracts of cardiomyocytes was measured by ELISA. Values are the means \pm SEM $(n=6-8)$ and are expressed as multiples of the control. ${ }^{*} \mathrm{P}<0.05$ vs. control; ${ }^{\#} \mathrm{P}<0.05$ vs. Ang II alone.

\section{Results}

TMP attenuates the Ang II-induced increase in protein synthesis and $\beta$-MHC mRNA expression. First, we measured the incorporation of $\left[{ }^{3} \mathrm{H}\right]$ leucine and the mRNA expression of the hypertrophic marker gene, $\beta$-MHC, in the cardiomyocytes to investigate the anti-hypertrophic effects of TMP. As shown in Fig. 1, Ang II $(0.1 \mu \mathrm{M})$ increased $\left[{ }^{3} \mathrm{H}\right]$ leucine incorporation $(\mathrm{P}<0.05$, Fig. 1A) and $\beta$-MHC mRNA expression $(\mathrm{P}<0.05$, Fig. 1B); however, this increase was inhibited by TMP (0.001-1.0 mM) in a dose-dependent manner. Of note, TMP $(1.0 \mathrm{mM})$ alone had no effect on $\left[{ }^{3} \mathrm{H}\right]$ leucine uptake or $\beta-\mathrm{MHC}$ mRNA expression.

TMP prevents Ang II-induced NF- $\kappa B$ activation and translocation. We then investigated whether TMP regulates the Ang II-induced activation of the NF- $\kappa$ B pathway. As shown in Fig. 2, treatment with Ang II for $24 \mathrm{~h}$ increased the protein levels of phosphorylated NF- $\mathrm{B}$ p65 (Fig. 2A) and the NF- $\kappa$ B-DNA binding activity (Fig. $2 \mathrm{~B}$ ) in the cardiomyocytes. Conversely, TMP prevented these effects induced by Ang II.
Anti-hypertrophic effects of TMP are associated with inhibition of the NF- $\kappa$ B pathway. To investigate whether the modulation of $\mathrm{NF}-\kappa \mathrm{B}$ pathway is responsible for the anti-hypertrophic effects of TMP, the NF- $\kappa$ B inhibitor, PDTC $(100 \mu \mathrm{M})$, was used in this study. The cardiomyocytes were treated with Ang II $(0.1 \mu \mathrm{M})$ for $24 \mathrm{~h}$ in the presence or absence of PDTC $(100 \mu \mathrm{M})$. First, we determined the specificity of the inhibitor by western blot analysis. As shown in Fig. 3, the NF- $\kappa$ B inhibitor markedly inhibited the Ang II-induced upregulation of phosphorylated NF- $\kappa \mathrm{B}$ p65 (Fig. 3A) and the NF- $\kappa$ B-DNA binding activity (Fig. $3 \mathrm{~B}$ ) in the cardiomyocytes. In addition, the NF- $\mathrm{B}$ inhibitor significantly inhibited the Ang II-induced cardiomyocyte hypertrophy, as evidenced by the decrease in $\left[{ }^{3} \mathrm{H}\right]$ leucine incorporation (Fig. 4A) and $\beta$-MHC mRNA expression (Fig. 4B). Of note, PDTC alone had no effect on $\left[{ }^{3} \mathrm{H}\right]$ leucine incorporation and $\beta$-MHC mRNA expression. Thus, the modulation of the $\mathrm{NF}-\kappa \mathrm{B}$ pathway may be one of the mechanisms involved in the anti-hypertrophic effects of TMP.

TMP inhibits the Ang II-induced upregulation of TNF- $\alpha$ mRNA expression and protein secretion through the suppres- 

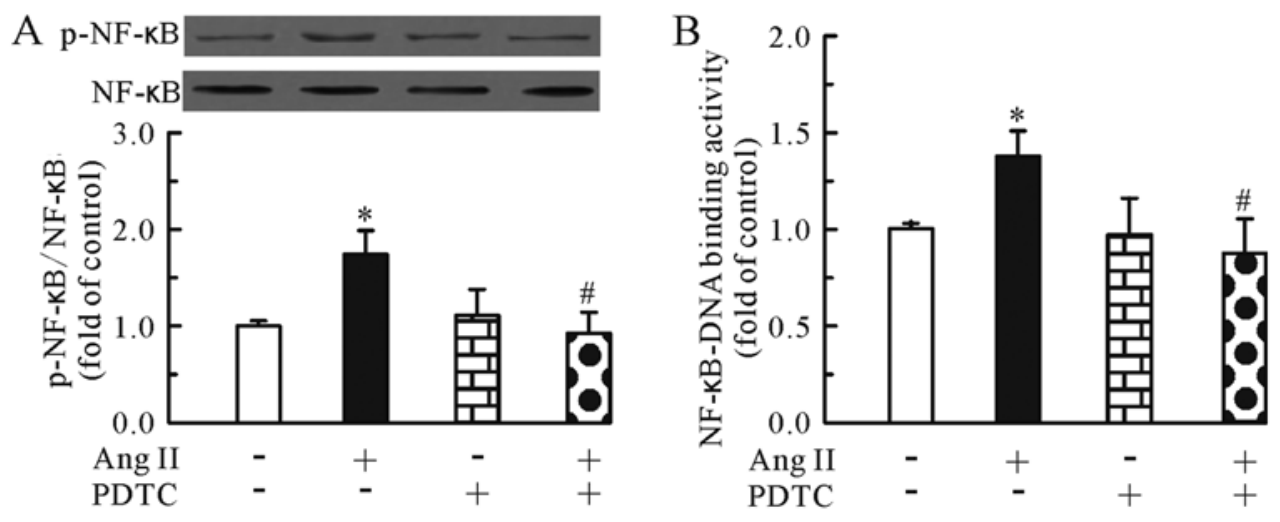

Figure 3. Pyrrolidine dithiocarbamate (PDTC) inhibits the angiotensin II (Ang II)-induced increase in the protein levels of phosphorylated NF- $\mathrm{B}$ p p65 in cardiomyocytes. Cultured cardiomyocytes were treated with $0.1 \mu \mathrm{M}$ Ang II in the presence or absence of $100 \mu \mathrm{M}$ PDTC (a NF- $\mathrm{kB}$ inhibitor) on culture day 3 .

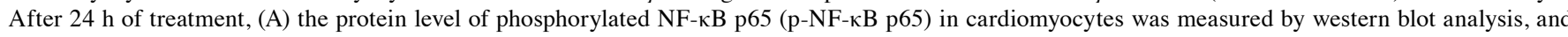
(B) the NF-кB-DNA binding activity in nuclear extracts of cardiomyocytes was measured by ELISA. Values are the means \pm SEM $(n=6-8)$ and are expressed as multiples of the control. ${ }^{*} \mathrm{P}<0.05$ vs. control; ${ }^{*} \mathrm{P}<0.05$ vs. Ang II alone.
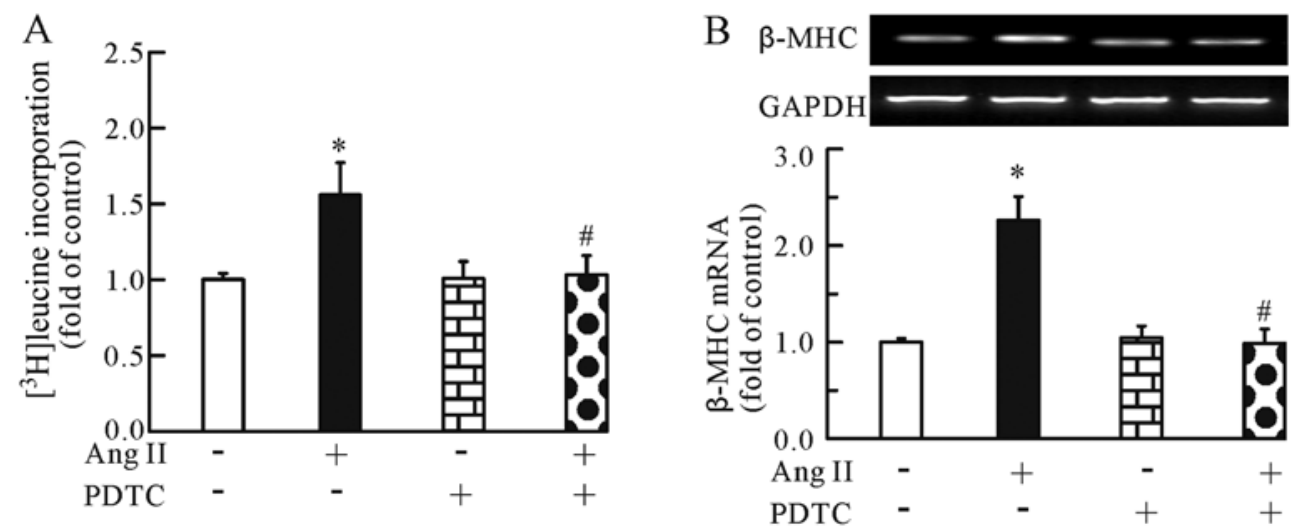

Figure 4. Inhibition of NF- $\kappa \mathrm{B}$ attenuates angiotensin II (Ang II)-induced hypertrophy in cardiomyocytes. Cultured caridiomyocytes were treated with $0.1 \mu \mathrm{M}$ Ang II in the presence or absence of $100 \mu \mathrm{M}$ pyrrolidine dithiocarbamate (PDTC) on culture day 3. After $24 \mathrm{~h}$ of treatment, (A) the incorporation of [ $\left.{ }^{3} \mathrm{H}\right] \mathrm{leucine}$, and (B) the $\beta$-MHC mRNA level was measured. Values are the means \pm SEM $(n=6-8)$ and are expressed as multiples of the control. " $\mathrm{P}<0.05 \mathrm{vs}$. control; ${ }^{*} \mathrm{P}<0.05$ vs. Ang II alone.
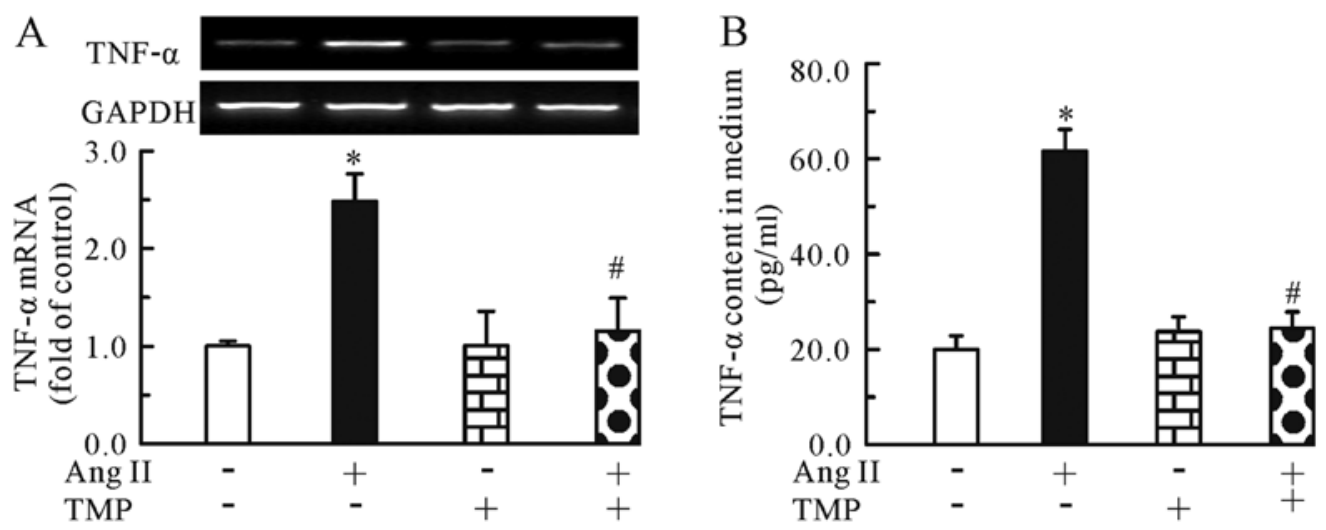

Figure 5. Tetramethylpyrazine (TMP) inhibits angiotensin II (Ang II)-induced upregulation of TNF- $\alpha$ secretion and expression in cardiomyocytes. Cultured cardiomyocytes were treated with Ang II $(0.1 \mu \mathrm{M})$ or TMP $(1.0 \mathrm{mM})$ alone, or their combination on culture day 3 . After $24 \mathrm{~h}$ of treatment, (A) the mRNA level of TNF- $\alpha$ in the cardiomyocytes was determined by real-time PCR, and (B) the protein content of TNF- $\alpha$ in the culture supernatants was determined by ELISA. Values are the means \pm SEM $(n=6-8)$ and are expressed as multiples of the control. ${ }^{*} \mathrm{P}<0.05$ vs. control; ${ }^{\#} \mathrm{P}<0.05$ vs. Ang II alone.

sion of the $N F-\kappa B$ pathway. Further experiments revealed the effects of TMP on the mRNA expression and protein secretion of TNF- $\alpha$. As shown in Fig. 5, Ang II $(0.1 \mu \mathrm{M})$ increased the
mRNA expression (Fig. 5A) and protein secretion of TNF- $\alpha$ (Fig. 5B), whereas TMP (1.0 mM) markedly inhibited these effects induced by Ang II. In addition, we found that compared 
A
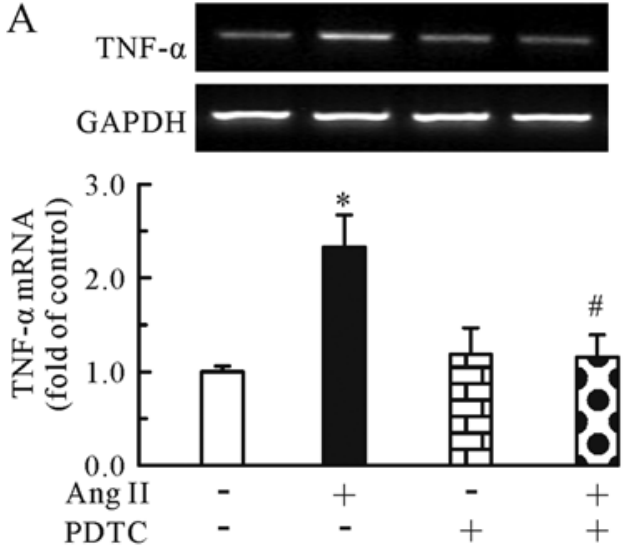

B

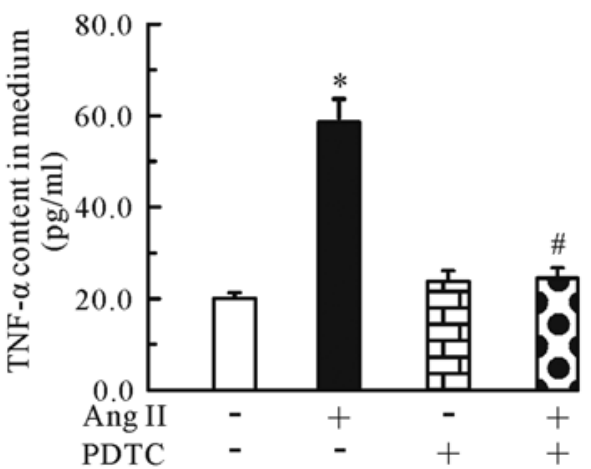

Figure 6. Inhibition of NF- $\mathrm{B}$ attenuates the angiotensin II (Ang II)-induced increase in TNF- $\alpha$ secretion and expression in cardiomyocytes. Cultured caridiomyocytes were treated with $0.1 \mu \mathrm{M}$ Ang II in the presence or absence of $100 \mu \mathrm{M}$ pyrrolidine dithiocarbamate (PDTC) on culture day 3 . After $24 \mathrm{~h}$ of treatment, (A) the mRNA level of TNF- $\alpha$ in the cardiomyocytes was determined by real-time PCR, and (B) the protein content of TNF- $\alpha$ in the culture supernatants was determined by ELISA. Values are the means \pm SEM $(n=6-8)$ and are expressed as multiples of the control. ${ }^{*} \mathrm{P}<0.05$ vs. control; ${ }^{*} \mathrm{P}<0.05$ vs. Ang II alone.

to treatment with Ang II $(0.1 \mu \mathrm{M})$ alone, the combined treatment of Ang II and PDTC $(100 \mu \mathrm{M})$ significantly reduced the mRNA expression (Fig. 6A) and protein secretion (Fig. 6B) of TNF- $\alpha$. Thus, TMP inhibited the Ang II-induced upregulation of TNF- $\alpha$ mRNA expression and protein secretion through the inhibition of the $\mathrm{NF}-\kappa \mathrm{B}$ pathway.

\section{Discussion}

The present study demonstrated that Ang II induced hypertrophic growth in neonatal cardiomyocytes, as evidenced by the increase in $\left[{ }^{3} \mathrm{H}\right]$ leucine incorporation and $\beta$-MHC mRNA expression, which was significantly inhibited by treatment with TMP. Ang II induced NF- $\kappa \mathrm{B}$ activation in the cardiomyocytes, whereas TMP decreased the levels of phosphorylated NF- $\kappa$ B. In addition, TMP inhibited the Ang II-stimulated mRNA expression and protein secretion of TNF- $\alpha$ in the cardiomyocytes, which was dependent on $\mathrm{NF}-\kappa \mathrm{B}$.

Previous in vivo and in vitro studies support an important protective role of TMP (also known as ligustrazine) in cardiac diseases. First, TMP exerts vasodilatory effects by affecting the release of the vasoactive substances, thromboxane A2 $\left(\mathrm{TXA}_{2}\right)$ and prostacyclin $\left(\mathrm{PGI}_{2}\right)$, in isolated rat hearts, which may contribute to its beneficial effects in myocardial hypoxia or ischemia (14). Second, TMP has been reported to reduce ischemia-induced ventricular arrhythmias (7), and the possible ionic mechanism for the anti-arrhythmic effect of TMP may involve its regulation of cardiomyocyte ion channels, such as L-type $\mathrm{Ca}^{2+}$ channels (15). Third, TMP has also been suggested as a potent antioxidant with efficacy in lipid peroxidationinduced heart toxicity (9). Furthermore, the protective role of TMP in burn-induced myocardial injury has been suggested to be associated with its inhibition of the release of TNF- $\alpha$ (16). Although a recent study demonstrated that TMP exerts protective effects against dilated cardiomyopathy in transgenic mice (17), the role of TMP in cardiac hypertrophy and its possible mechanisms of action remain unknown. In the present study, we first demonstrated that TMP inhibited Ang II-induced cardiomyocyte hypertrophy in vitro and the release of the proinflammatory cytokine, TNF- $\alpha$, in cardiomyocytes.

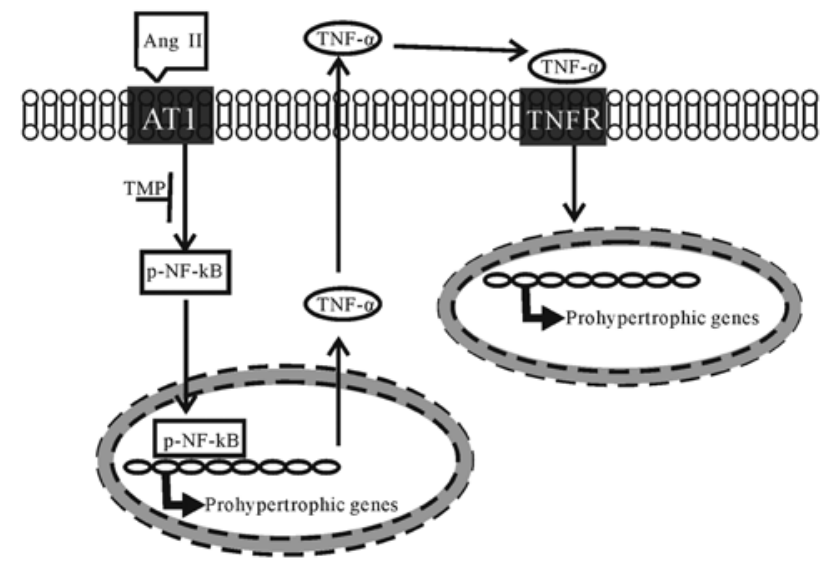

Figure 7. The proposed mechanisms underlying the anti-hypertrophic effects of tetramethylpyrazine (TMP).

The underlying molecular mechanisms of cardiac hypertrophy are extremely complex and involve intricate interactions of multiple signaling pathways. Of these, the involvement of the $\mathrm{NF}-\kappa \mathrm{B}$ pathway in the pathogenesis of cardiac hypertrophy has been well established $(4,18,19)$. Under pathological conditions, a number of hypertrophic factors, such as Ang II (20) and isoproterenol (21) activate the $\mathrm{NF}-\kappa \mathrm{B}$ pathway in cardiomyocytes. In unstimulated cells, the major form of $\mathrm{NF}-\kappa \mathrm{B}$ complexes is an inactive heterodimer composed of the p50 and p65 subunits and is sequestered into the cytoplasm through its interaction with specific inhibitory proteins, such as IкB (22). Extracellular stimuli that activate $N F-\kappa B$ induce the rapid phosphorylation of $\mathrm{I} \kappa \mathrm{B}$ and subsequently, the dissociation of NF- $\kappa \mathrm{B}$ from I $\mathrm{IB}$. Once activated, activated $N F-\kappa B$ translocates to the nucleus, where it acts as a transcription factor by binding to regulatory DNA sequences, triggering hypertrophic gene expression (23). The inhibition of NF- $\kappa \mathrm{B}$ has been demonstrated to exert antihypertrophic effects in cardiomyocytes $(4,24)$. In the present study, we therefore hypothesized that the inhibition of the $\mathrm{NF}-\kappa \mathrm{B}$ pathway is the molecular basis for the anti-hypertrophic effects of TMP. Our results revealed that treatment with TMP markedly suppressed the Ang II-induced secretion of phos- 
phorylated NF- $\mathrm{KB}$ p65 in the cardiomyocytes; the inhibition of $\mathrm{NF}-\kappa \mathrm{B}$ by the specific inhibitor, PDTC, significantly inhibited Ang II-induced hypertrophy; thus, the inhibition of NF- $\kappa$ B may be one of the mechanisms behind the anti-hypertrophic effects of TMP. However, the mechanisms by which TMP inhibits the $\mathrm{NF}-\mathrm{kB}$ pathway remain unknown. Thus, further studies are required to clarify this issue.

Although the direct pro-hypertrophic effects of TNF- $\alpha$ have been well documented $(10,25-27)$, there is also evidence to suggest that TNF- $\alpha$ mediates the effects of other hypertrophic factors in an autocrine or paracrine fashion. Previous studies have shown that Ang II increases the expression of TNF- $\alpha$ in cardiomyocytes (28). In the present study, we also found that Ang II induced TNF- $\alpha$ secretion and expression in neonatal cardiomyocytes. In TNF- $\alpha$ knockout mice, a previous study demonstrated that TNF- $\alpha$ plays a role in mediating chronic Ang II-induced effects on blood pressure and cardiac hypertrophy (29). Taken together, these data suggest that the autocrine release of TNF- $\alpha$ mediates the hypertrophic effects of Ang II. In this study, treatment with TMP attenuated the Ang II-induced secretion and expression of TNF- $\alpha$, which may also contribute to the anti-hypertrophic effects of TMP.

In conclusion, the present study investigated the therapeutic effects of TMP on myocardial hypertrophy induced by Ang II. To our knowledge, our results demonstrate for the first time that TMP prevents Ang II-induced hypertrophy in neonatal cardiomyocytes, which is attributed to its inhibition of the NF- $\mathrm{KB}$ pathway and TNF- $\alpha$ secretion in cardiomyocytes (the proposed mechanisms underlying the anti-hypertrophic effects of TMP are illustrated in Fig. 7). These findings raise the possibility of developing TMP as a therapeutic drug for cardiac hypertrophy.

\section{Acknowledgements}

This study was supported by grants from the Science and Technology Research Foundation of Hubei Provincial Educational Department (no. B20122804) and the Science Fund of Hubei Science and Technology University (nos. BK1104, KY0887 and ZX1201).

\section{References}

1. Levy D, Garrison RJ, Savage DD, Kannel WB and Castelli WP: Prognostic implications of echocardiographically determined left ventricular mass in the Framingham Heart Study. N Engl J Med 322: 1561-1566, 1990

2. Sadoshima J and Izumo S: Molecular characterization of angiotensin II - induced hypertrophy of cardiac myocytes and hyperplasia of cardiac fibroblasts. Critical role of the AT1 receptor subtype. Circ Res 73: 413-423, 1993.

3. Lee KH, Jang Y and Chung JH: Heat shock protein 90 regulates IkappaB kinase complex and NF-kappaB activation in angiotensin II-induced cardiac cell hypertrophy. Exp Mol Med 42: 703-711, 2010

4. Gupta S, Young D, Maitra RK, et al: Prevention of cardiac hypertrophy and heart failure by silencing of NF-kappaB. J Mol Biol 375: 637-649, 2008.

5. Chen KJ and Chen K: Ischemic stroke treated with Ligusticum chuanxiong. Chin Med J (Engl) 105: 870-873, 1992.

6. Sutter MC and Wang YX: Recent cardiovascular drugs from Chinese medicinal plants. Cardiovasc Res 27: 1891-1901, 1993.

7. Feng J, Wu G and Tang S: The effects of tetramethylpyrazine on the incidence of arrhythmias and the release of PGI2 and TXA2 in the ischemic rat heart. Planta Med 65: 268-270, 1999.
8. Fan L, Wang K, Shi Z, Die J, Wang C and Dang X: Tetramethylpyrazine protects spinal cord and reduces inflammation in a rat model of spinal cord ischemia-reperfusion injury. J Vasc Surg 54: 192-200, 2011.

9. Liu CF, Lin CH, Chen CF, Huang TC and Lin SC: Antioxidative effects of tetramethylpyrazine on acute ethanol-induced lipid peroxidation. Am J Chin Med 33: 981-988, 2005.

10. Wang GJ, Wang HX, Yao YS, Guo LY and Liu P: The role of $\mathrm{Ca}^{2+} /$ calmodulin-dependent protein kinase II and calcineurin in TNF-alpha-induced myocardial hypertrophy. Braz J Med Biol Res 45: 1045-1051, 2012.

11. Hu Y, Li T, Wang Y, et al: Tollip attenuated the hypertrophic response of cardiomyocytes induced by IL-1beta. Front Biosci 14: 2747-2756, 2009

12. Yokoyama T, Sekiguchi K, Tanaka T, et al: Angiotensin II and mechanical stretch induce production of tumor necrosis factor in cardiac fibroblasts. Am J Physiol 276: H1968-H1976, 1999.

13. Huang Y, Zhang H, Shao Z, et al: Suppression of endothelin-1-induced cardiac myocyte hypertrophy by PPAR agonists: role of diacylglycerol kinase zeta. Cardiovasc Res 90: 267-275, 2011.

14. Feng J, Liu R, Wu G and Tang S: Effects of tetramethylpyrazine on the release of PGI2 and TXA2 in the hypoxic isolated rat heart. Mol Cell Biochem 167: 153-158, 1997.

15. Zou LY, Hao XM, Zhang GQ, Zhang M, Guo JH and Liu TF: Effect of tetramethyl pyrazine on L-type calcium channel in rat ventricular myocytes. Can J Physiol Pharmacol 79: 621-626, 2001.

16. Gao S, Chen ZW, Zheng H and Chen XL: Ligustrazine attenuates acute myocardium injury after thermal trauma. Burns 33 : 321-327, 2007.

17. Zhao HP, Lu D, Zhang W, et al: Protective action of tetramethylpyrazine phosphate against dilated cardiomyopathy in cTnT(R141W) transgenic mice. Acta Pharmacol Sin 31: 281-288, 2010.

18. Rajapurohitam V, Kilic A, Javadov S and Karmazyn M: Role of NF-kappaB and p38 MAPK activation in mediating angiotensin II and endothelin-1-induced stimulation in leptin production and cardiomyocyte hypertrophy. Mol Cell Biochem 366: 287-297, 2012.

19. Liu Q, Chen Y, Auger-Messier M and Molkentin JD: Interaction between NFkappaB and NFAT coordinates cardiac hypertrophy and pathological remodeling. Circ Res 110: 1077-1086, 2012.

20. Valente AJ, Clark RA, Siddesha JM, Siebenlist U and Chandrasekar B: CIKS (Act1 or TRAF3IP2) mediates angiotensin-II-induced Interleukin-18 expression, and Nox2dependent cardiomyocyte hypertrophy. J Mol Cell Cardiol 53: 113-124, 2012.

21. Freund C, Schmidt-Ullrich R, Baurand A, et al: Requirement of nuclear factor-kappaB in angiotensin II- and isoproterenolinduced cardiac hypertrophy in vivo. Circulation 111: 2319-2325, 2005.

22. Wang D and Baldwin AS Jr: Activation of nuclear factor-kappaBdependent transcription by tumor necrosis factor-alpha is mediated through phosphorylation of RelA/p65 on serine 529 . J Biol Chem 273: 29411-29416, 1998.

23. Baldwin AS Jr: The NF-kappa B and I kappa B proteins: new discoveries and insights. Annu Rev Immunol 14: 649-683, 1996.

24. Kawano S, Kubota T, Monden Y, et al: Blockade of NF-kappaB ameliorates myocardial hypertrophy in response to chronic infusion of angiotensin II. Cardiovasc Res 67: 689-698, 2005.

25. Sun M, Chen M, Dawood F, et al: Tumor necrosis factor-alpha mediates cardiac remodeling and ventricular dysfunction after pressure overload state. Circulation 115: 1398-1407, 2007.

26. Janczewski AM,Kadokami T, Lemster B, Frye CS, McTiernan CF and Feldman AM: Morphological and functional changes in cardiac myocytes isolated from mice overexpressing TNF-alpha. Am J Physiol Heart Circ Physiol 284: H960-H969, 2003.

27. Nakamura K, Fushimi K, Kouchi H, et al: Inhibitory effects of antioxidants on neonatal rat cardiac myocyte hypertrophy induced by tumor necrosis factor-alpha and angiotensin II. Circulation 98: 794-799, 1998.

28. Ock S, Ahn J, Lee SH, et al: Receptor activator of nuclear factorkappaB ligand is a novel inducer of myocardial inflammation. Cardiovasc Res 94: 105-114, 2012.

29. Sriramula S, Haque M, Majid DS and Francis J: Involvement of tumor necrosis factor-alpha in angiotensin II-mediated effects on salt appetite, hypertension, and cardiac hypertrophy. Hypertension 51: 1345-1351, 2008. 